\section{Freeze and Frost Protection with Aqueous Foam - Foam Development}

\author{
Christopher Y. Choi, ${ }^{1}$ \\ Werner Zimmt, ${ }^{2}$ and \\ Gene Giacomelli ${ }^{3}$
}

Additional index words. freeze and frost damage, plant cold protection, radiation shield, biodegradable aqueous foam, and mulching.

Summary. Aqueous foam was developed to serve as a barrier to conductive, convective, and radiative heat transfer. Through the use of a bulking agent, the physical properties of gelatin-based foam were more stable, adhesive, biodegradable, and long lasting. The phytotoxicity, possible environmental hazard and removal of the foam were also considered.

Resistance to freezing-thawing, heating-evaporation, and wind were evaluated. Studies to determine the foam's long-term stability under field weather conditions were completed. The handling and performance characteristics of the foam necessary for development of this application were determined. Factors that affect the physical properties and the utilization of the foam were quantified. These included the proportions of the foam components, the mixing temperature of the prefoam solution, the application temperature, and the rate of foam generation. The newly developed foam might be ideal for freeze and frost protection in agriculture.

The cost of publishing this paper was defrayed in part by the payment of page charges. Under postal regulations, this paper therefore must be hereby marked advertisement solely to indicate this fact.

${ }^{1}$ Assistant professor, Department of Agricultural and Biosystems Engineering, University of Arizona, Tucson, Ariz.

${ }^{2}$ Adjunct professor, Department of Agricultural and Biosystems Engineering, University of Arizona, Tucson, Ariz.

${ }^{3}$ Professor, Department of Bioresource Engineering, Cook College, Rutgers University, New Brunswick, N.J.
$\mathrm{F}$ reezes occur due to convective heat loss during windy and severe cold periods, while frosts are due to radiative heat loss to the cold sky during calm, clear nights. In general, freeze-frost damage takes three forms: 1) immediate damage - the current yields cannot be marketed, and/or foliage is damaged, 2) long-term damage-replacement of badly damaged perennial crops such as orchard or grove trees delays production for several years, and 3 ) risk avoidance damage-farmers whose land would otherwise support higher-income frost sensitive crops do not plant them for fear of loss. In the United States, freeze-frost damage is common in many states every year, and sometimes it occurs repeatedly. For example, successive cold damages occurred in January 1981, January 1982, December 1983, and January 1985 in Florida (Polopolus and Gunter, 1985). In particular, the monetary losses due to the 1983 freeze were estimated to be more than $\$ 2$ billion dollars in Florida alone. The same freeze also decimated much of the citrus (Citrus L.) acreage in Texas the day before the Florida damage.

The recurring widespread losses of agricultural commodities due to freeze-frost damage have been the driving force behind the continued research in crop protection during the last few decades. In cases where the cold period is severe and prolonged with a danger of freezing, the existing techniques are either inadequate to protect trees or too costly (Reiger, 1989). Therefore, any effective, economically viable, environmentally responsible means of protection against freeze and frost damage by elevating temperatures by only a few degrees may be of inestimable value to the agricultural industry in the United States and around the world.

There have been many cold protection techniques used such as artificial wind or heat generation, or the use of phase change energy from spray irrigation water. One alternative is the application of aqueous foam over crops for both freeze and frost protection. The scientific justification for the present research is 2 -fold: 1 ) aqueous foam is a good insulator with relatively low thermal conductivity, and 2 ) aqueous foam is an excellent radiation shield, since water is opaque to radiation.

Previous agricultural foam re- 
search demonstrated the effectiveness of aqueous foam (Batholic, 1985), while important technical challenges for field application were still unsolved.

Therefore, the primary objectives of the present study were to develop stable, inexpensive, adhesive, long-lasting aqueous foam. The main hypothesis is that aqueous foam can be applied readily to any crop and may serve as an effective barrier against convective and radiative heat loss for a desirable time period.

In the present paper, the development and evaluation of long-lasting foam will be discussed in detail. In the paper by Choi and Giacomelli (1999), the results of field experiments involving freeze and frost protection are presented.

\section{Literature review}

Frost-freeze control has included the use of orchard heaters or the burning of old tires, coal, hay or similar combustibles. In low wind conditions, these systems have been effective in raising bud-fruit temperatures sufficiently to save crops. However, the burning of old tires is discouraged due to environmental considerations. Wind machines are effective in certain areas for frost protection where inversion frosts are the normal cold hazard; however, they are not effective against freezes accompanying cold fronts and high winds.

Overhead sprinkling either by conventional or microirrigation systems has been extensively used and has proven to be a successful technique for freeze protection in Texas, Florida, and other areas. However, these systems can cause severe damage due to limb or stem breakage from ice load on trees or plants and are not effective in freezing conditions accompanied by high winds. In Arizona similar attempts at frost protection had disastrous consequences because in such a dry climate, the sprayed water evaporated instantly and caused a drop in air temperature. Systems designed to eliminate nucleating bacteria, which is necessary for ice crystal formation, have been tried, but the results have not been consistently beneficial (Ashworth, 1992). Freeze and frost protection systems using nonaqueous insulation materials have been reported to minimize the freeze problem in some areas (Rieger, 1989).

Many aqueous foams have been carefully engineered to perform specific tasks such as fire fighting, crop treatment, the muffling of explosions, dust suppression, and even for pest control. A nontoxic $\mathrm{CO}_{2}$ foam was designed and successfully tested to spread over crops or substrate and to persist for a sufficient time period such that insects suffocated in the anoxic foam (Choi et al., 1997). At the University of Arizona, low-density aqueous foam was used as a nighttime greenhouse insulation system to keep heat from escaping through the roof glazing. Each evening the foam was pumped between the two layers of translucent plastic that form the roof of the structure. As the foam collapsed the liquid was collected and stored, and made available for reuse (Jensen, 1977). In addition, aqueous foam has been tested and used in agriculture as a carrier for herbicides and pesticides (Blackmon et al., 1972; MagnusonHawkins and Gahlinger, 1996; Whitney et al., 1976).

For freeze and frost protection, many different types of aqueous foam have been introduced and tested since the 1950s. These foams were good insulators with relatively low thermal conductivity $\approx 0.11 \mathrm{~W} \cdot \mathrm{m}^{-1} \cdot{ }^{\circ} \mathrm{C}^{-1}$ (Braud and Chessness, 1970). Successful demonstrations of freeze protection have been reported under field conditions for low-profile plants in the United States, Russia, and Canada. Long-lasting (from several hours to $>24 \mathrm{~h}$ ), nonphytotoxic foams with different combinations of agents were identified, and the overall cost was reportedly reasonable for extensive field application (Barfield and Gerber, 1979; Reiger, 1989). The application of foam over trees was, however, unsuccessful in moderating canopy temperatures (Bartholic, 1985).

Recently, work on foam distribution systems has been developed in Israel. Five years of research by a group of researchers culminated in the construction of a low-pressure overhead foam generator which could be deployed in the field and connected to the existing irrigation pipe network. A concentrated foaming solution was injected near the main water inlet. Air sucked into the foam generator due to the fluid flow generated water-based foam. Several foam solutions were developed and tested (Krasovitski et al., 1995 and 1996), which proved stable for 6 to $8 \mathrm{~h}$ in temperatures below $0{ }^{\circ} \mathrm{C}$ $\left(32^{\circ} \mathrm{F}\right)$, and caused no harm to plants or the environment. The air to water ratio of the foam was $\approx 50: 1$, which produced foam with relatively low viscosity, that was appropriate for low profile plants.

In the United States, many researchers performed and reported on extensive laboratory experiments and successful field applications from the late 1960s through the 1980s (Braud and Chesness, 1970; Braud et al., 1971; Taylor et al., 1983; Rieger, 1989). The foams used in these studies were, in fact, excellent temporary insulators. These foams, however, were weak and unstable under windy conditions and lasted at best only one day. They also collapsed at 10 to $25^{\circ} \mathrm{C}\left(50\right.$ to $\left.77^{\circ} \mathrm{F}\right)$ which are typical of winter daytime air temperatures of subtropical regions. Upon a freeze-frost forecast, foam would be sprayed immediately over the tree canopies, branches and trunks during the day. However the foams applied on a sunny warm day would often collapse before the cold front arrived. In addition, the foams did not particularly adhere to the crop at any given temperature. On angled leaf surfaces or upright tree trunks, these foams tended to flow down immediately after application.

These various foam covers potentially could have benefited low profile, high value crops. However, it was difficult to cover canopies, branches and trunks of freestanding tall trees with these foams. The long-term benefits in hostile environments (windy and warm daytime temperature conditions) were marginal. Except in application to low profile crops, aqueous foams failed to become technically and economically viable, not because they did not work for both freeze and frost protection, but because the problems of foam placement and longevity had not been fully explored and solved.

\section{Development of long- lasting aqueous foam}

A series of experiments was performed to evaluate foam properties, while searching for foams that would last for a minimum of several days in various weather conditions, would be sufficiently adhesive to endure windy conditions on tree trunks and on canopies of freestanding tall trees, would be nontoxic to plants and environment, and would readily degrade after its useful period. 


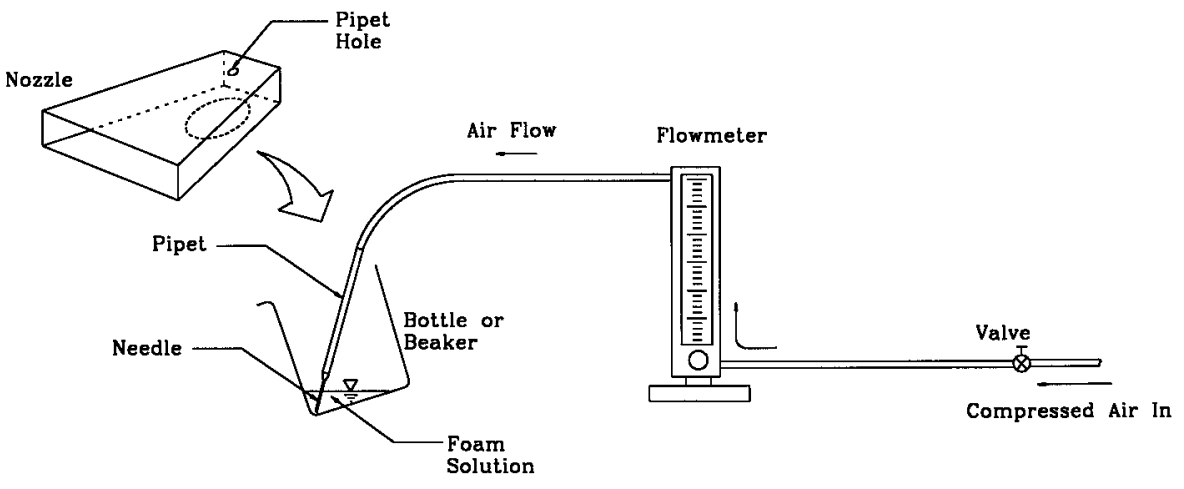

(a)

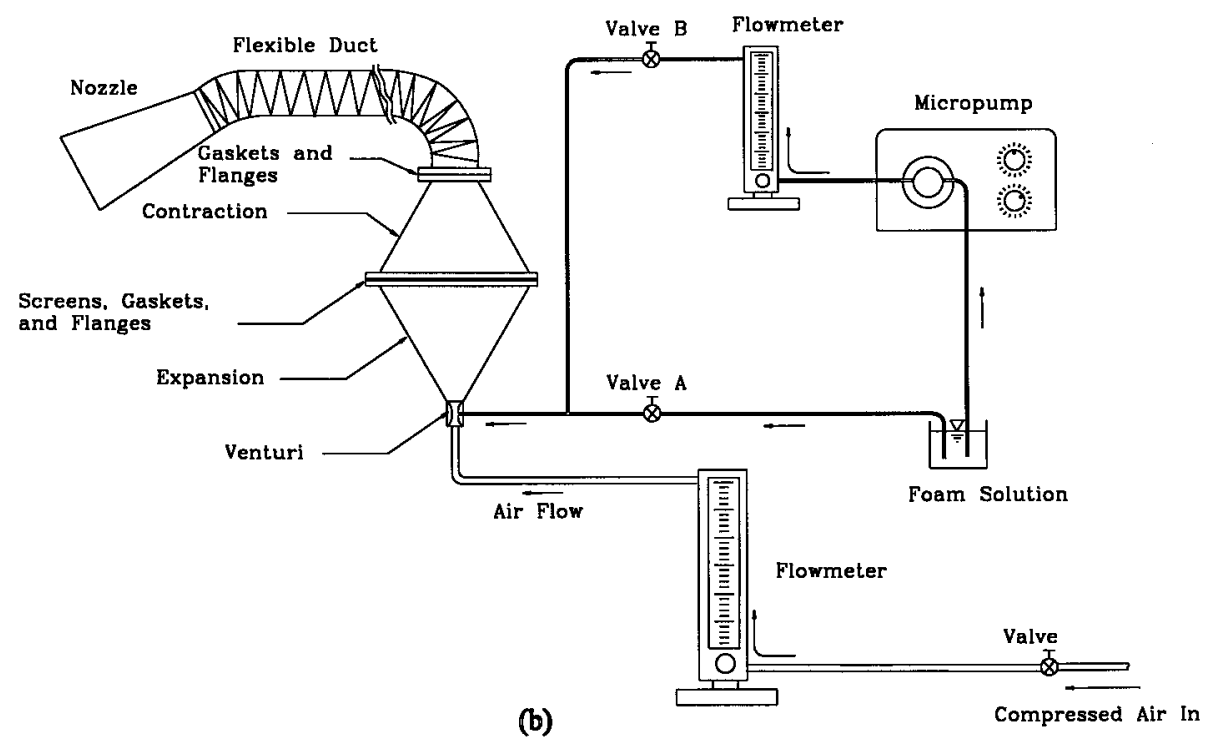

Fig. 1. Laboratory experimental setup for foam generation. (a) $A$ schematic of the foaming process with a needle and beaker. (b) $A$ venturi-type foam generator with a micropump.

\section{Formulation and testing procedure}

A simple experimental process for testing foam formulations was developed so that numerous combinations of chemicals could be tested and promising compositions identified. As a standard procedure, $25 \mathrm{~mL}(0.85 \mathrm{fl} \mathrm{oz})$ liquid foam solution was poured into a l-L (0.26-gal) plastic beaker. The beaker was tilted, and a glass pipette with a hypodermic needle $(0.24 \mathrm{~mm}$ ID, Becton-Dickinson \& Co., N.J.) was inserted into the liquid. A controlled stream of air was blown through the needle, and the time and solution temperature were noted. A schematic of the foaming process is shown in Fig. la. A similar foam generation tech- turi was sufficient to suck the solution into the foam generator. The rate of liquid flow and airflow also had to be controlled; too much liquid in the venturi reduced foam stability, with too little liquid, the foam would not form. Later the venturi section was replaced with a micropump in an effort to accurately control the flow rate of the solution as shown in Fig. Ib. Consistent foam was achieved using this design, with proper control of the flow rates of the air and solution. This device was adequate to produce a relatively large volume of foam $\left[>10 \mathrm{~L} \cdot \mathrm{min}^{-1}(2.64\right.$ $\mathrm{gal} / \mathrm{min}$ )], although it was not used for the subsequent laboratory and field experiments.

\section{Foam development}

There were hundreds of possible chemicals and formulations to examine. Chemicals were chosen and tested with numerous formulations based on literature survey and hypothesis. Among these attempts, the formulation with gelatin and sucrose was most successful.

Gelatin has been examined extensively as agricultural foam to reduce crop loss from cold damage because of its ability to solidify (gel) at low temperatures. A number of gelatin-based formulations that might generate stable foam were considered, and screening tests were completed. Most of the trial foam formulations consisted of a dilute solution of gelatin, a wetting agent that would help the solution to foam, and small amounts of stabilizing agents to keep the foams from collapsing rapidly. Without the wetting agents, these foams would collapse as soon as the water evaporated. Table 1 lists the gelatins, bulking agents, and other additives examined, and the ideal formulation based on our laboratory tests is shown in Table 2 .

It was hypothesized that a foam containing a substantial quantity of solid material to give it strength would have a much better chance of lasting for a long time period, even after all the water had evaporated. A study of the literature about gelatin suggested sucrose as the most promising candidate (Ward, 1977), although other carbohydrates such as sorbitol, dextro-maltose derivatives, and some hydrolyzed proteins and starch derivatives were considered. Sugar is extremely compatible with and soluble in gelatin solutions; it can be added in any amount; 
Table 1. List of gelatins, bulking agents, and other additives examined for laboratory foam generation experiments

\begin{tabular}{lll}
\hline $\begin{array}{l}\text { Chemical } \\
\text { classification }\end{array}$ & $\begin{array}{l}\text { Chemical } \\
\text { brand name }\end{array}$ & Manufacturer \\
\hline Gelatins & VEEGEE Superwhip Gelatin & VYSE Corp. Schiller Park, Ill. \\
& DynaGel 250 Bloom Gelatin & Dynagel Inc., Calumet City, Ill. \\
Bulking Agents & Star-Dri 100,150 Maltodextrin & A.E. Staley Corp. Decator. Ill. \\
& Star-Pol 480 WSP, 560 WSP, 630 WSP) & American Maize-Products Co., Hammond, Ind. \\
& Amaizo 2711F & Takeda U.S.A., Orangeburg, N.Y. \\
& Citrus Pectin Slow Set Type ES & Proctor and Gamble, Cincinnati, Ohio \\
Surfactants & Orvus WA paste (30\% active sodium lauryl sulfate) & WITCO Corp, Houston, Texas \\
& Supralate C NF solid sodium lauryl sufate & Chemron Corp, Paso Robles, Calif. \\
& Sulfochem ALS, 30\% active ammonium lauryl sulfate & \\
& Maypon 4C hydrolyzed animal protein solution, & INOLEX Chemical Co., Philadelphia, Pa. \\
& potassium salt, 35\% solids & INOLEX Chemical Co., Philadelphia, Pa. \\
& SUPER PRO 5A TEA-COCO-Hydrolyzed animal & \\
& protein-sorbitol & \\
Other Additives & Sorbic acid & \\
& Potassium salt & \\
& Urea &
\end{tabular}

it is inexpensive, readily available, nontoxic and soluble in water. The major disadvantage of gelatin-sugar-based foams is their susceptibility to bacterial and fungal growth. Therefore, a small amount of potassium sorbate was used to reduce that problem.

A wetting agent to promote foam formation was also required. Of the various tested wetting agents, ammonium lauryl sulfate seemed to produce the best foam in the formulations considered. The top layer of the foam made with large quantities of sugar became more brittle and fragile than desired as the moisture on the surface evaporated. To solve this problem, glycerol was added as a plasticizer. If too much glycerol was added, the foam became tacky and weak under windy conditions.

To obtain the foam solution, water was heated to $\approx 60^{\circ} \mathrm{C}\left(140^{\circ} \mathrm{F}\right)$ with vigorous stirring, and the gelatin was added gradually over a $10-$ min period. As the gelatin was completely dissolved, the sugar was added and dissolved, followed by the other ingredients. The solution was cooled to $\approx 35^{\circ} \mathrm{C}\left(95^{\circ} \mathrm{F}\right)$ and poured into a storage container. Below $25{ }^{\circ} \mathrm{C}\left(77^{\circ} \mathrm{F}\right)$, the solution would solidify and could no longer be poured.

The temperature at which the gelling occurred could be controlled by adding urea to the formulation, and as more urea was added, the gelling temperature was lowered. This may be important in fieldwork since it is likely that temperatures at application time may be quite close to freezing, and the time and energy necessary to heat the solution above the gelling temperature may be inconvenient.

Foam formation is strongly influenced by ambient conditions (especially air temperature), the rates of air and fluid flow, and the temperature of the foam solution. If the temperature of the gelatin-sugar solution is too high, the foam will collapse during the formation period; if it is too low, the solution viscosity will be too high to form a good foam structure.

\section{Results and discussion}

Laboratory eXPERIMENTS. Foam was generated in a $1-\mathrm{L}(0.26$-gal $)$ beaker as described earlier and placed under the laboratory conditions [at $23 \pm$ $3{ }^{\circ} \mathrm{C}\left(73.4 \pm 5.4^{\circ} \mathrm{F}\right)$ and $30 \% \pm 15 \%$ relative humidity]. To study the significance of glycerol in the gelatinsugar foam, foams with and without glycerol were prepared. Undisturbed, both foams maintained their structure semipermanently in laboratory conditions. Repeated tests indicated that the volumetric reduction of the foam was $<10 \%$ per month after application. However, the dried top surface of the foam without glycerol became crusty and easily peeled off at the slightest disturbance. Glycerol increased both the stickiness and the persistence of the foam. It should be noted that the foaming ability was drastically reduced when the wetting agent was removed from the formulation.

Foam in the 1-L beaker was placed in a constant temperature oven (Isotemp Vacuum Oven 282A; Fisher Scientific, Pittsburgh, Pa.) to observe its longevity under warm subtropical conditions. The temperature was set consecutively at $30,40,50{ }^{\circ} \mathrm{C}(86$, $\left.104,122^{\circ} \mathrm{F}\right)$, and each temperature was maintained for $48 \mathrm{~h}$. No visible degradation of the foam structure was observed, although volumetric shrinkage did take place. A screen $[1.3 \times 1.3$ $\mathrm{cm}$ mesh size $(0.5 \mathrm{inch})]$ was prepared in order to study the foam shrinkage when all foam surfaces were exposed to air. About $15 \mathrm{~cm}$ long, $5 \mathrm{~cm}$ wide, $3 \mathrm{~cm}$ thick foam $(5.9 \times 2.0 \times 1.2 \mathrm{inch})$ was placed on the screen. The foam shrank $\approx 10 \%$ within $24 \mathrm{~h}$ and remained the same volume afterward. The volumetric loss was due mainly to the reduction in the foam thickness (depth) rather than lateral shrinkage (length or width). Higher oven temperatures accelerated the shrinkage and the drying of the foam surface; i.e., the soft and

Table 2. The ideal foam formulation chosen for the freeze-frost field experiments based on laboratory experiments.

\begin{tabular}{lc}
\hline Ingredients & $\begin{array}{c}\text { Percentage } \\
\text { (by wt) }\end{array}$ \\
\hline Water & 68.0 \\
Gelatin (Dynagel 250 Bloom) & 2.4 \\
Sucrose (Sugar) & 28.0 \\
Sulfochem ALS (10\% solids) & 0.5 \\
Glycerol & 1.0 \\
Potassium sorbate & 0.1 \\
\hline
\end{tabular}




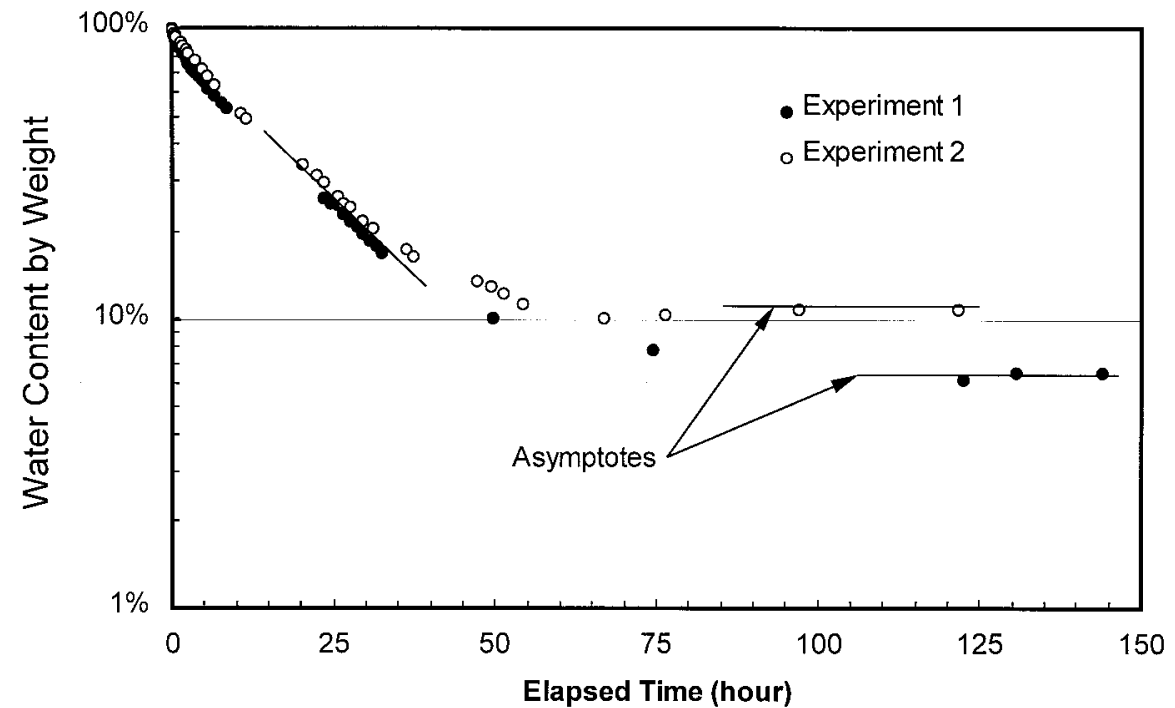

Fig. 2. Reduction of water in aqueous foams over a time period in laboratory conditions depicted in a semi-log scale.

moist texture of the foam surface quickly disappeared due to evaporation. Nevertheless, the foam maintained its original shape over the screen. After the oven experiments, the foam from the oven was placed in the laboratory at $23 \pm 3{ }^{\circ} \mathrm{C}\left(73.4 \pm 5.4^{\circ} \mathrm{F}\right)$ and $30 \% \pm 15 \%$ relative humidity for $>1$ week. No noticeable change in shape and volume was observed during this period.

The survival of the foam under freezing and thawing conditions was also examined. Beakers filled with foam were placed in a constant temperature freezer. Temperature was set at -10 and $-20^{\circ} \mathrm{C}\left(14\right.$ and $\left.-4^{\circ} \mathrm{F}\right)$ respectively. The foam immediately shrank to $\approx 70 \%$ of its original volume at both -10 and $-20{ }^{\circ} \mathrm{C}\left(14\right.$ and $\left.-4{ }^{\circ} \mathrm{F}\right)$. When the beakers were rapidly exposed to room temperature after $24 \mathrm{~h}$ in the freezer, the foam completely collapsed within an hour. Repeated experiments produced the same results. Alternatively, the beakers with foam were gradually thawed over 4 h; i.e., the beakers from the -10 and $-20^{\circ} \mathrm{C}\left(14\right.$ and $\left.-4{ }^{\circ} \mathrm{F}\right)$ freezers were placed in the $0^{\circ} \mathrm{C}\left(32^{\circ} \mathrm{F}\right)$ freezer for $\approx 4 \mathrm{~h}$. They were moved to a $5{ }^{\circ} \mathrm{C}\left(4 \mathrm{l}^{\circ} \mathrm{F}\right)$ refrigerator for $>4 \mathrm{~h}$; they were then exposed to room temperature. With gradual warming, the foam consistently maintained its volume and shape. The latter experiment closely simulates extreme weather conditions in nature. Thus, the foam may likely survive severe daily temperature fluctuations. foam solution during foam generation. The first and second foams weighed 45 and $62 \mathrm{~g}(0.10$ and 0.14 lb) respectively. The second foam also was slightly thicker, $6.5 \mathrm{~cm}$ (2.6 inch) as compared to $5 \mathrm{~cm}$ (2 inch), and the approximate foam densities were 0.013 $\mathrm{g} \cdot \mathrm{mL}^{-1}(1.7 \mathrm{oz} / \mathrm{gal})$ for the first experiment and $0.015 \mathrm{~g} \cdot \mathrm{mL}^{-1}(2.0 \mathrm{oz} /$ gal) for the second experiment when measured immediately after the foam generation. The prepared foam solution was $68 \%$ water by weight (see Table 2 ) and was placed on a $30 \times 23$ $\mathrm{cm}(11.8 \times 9.1$ inch $)$ Plexiglas plate.

As shown in Fig. 2, the fractions of water lost for both experiments were very similar throughout the experiment until they approached asymptotes. Water evaporated quickly in the beginning, and then the evaporation rate gradually slowed. After $24 \mathrm{~h}$, only $25 \%$ of the water remained in the foam. The rate was substantially reduced thereafter. Eventually, 7.8\% (by weight) of water used for foam generation remained in the first foam, while the denser and thicker second foam held $10.8 \%$ water. It appeared that foam density as well as its surface area limited the loss of water. It is interesting that the slopes for both cases were nearly linear after the first $5 \mathrm{~h}$ in a semilog graph. It is assumed that evaporation by advection was initially active on the surface, and that constant diffu-

Fig. 3. Foam strength experiments in a wind tunnel at various wind speeds and temperatures.

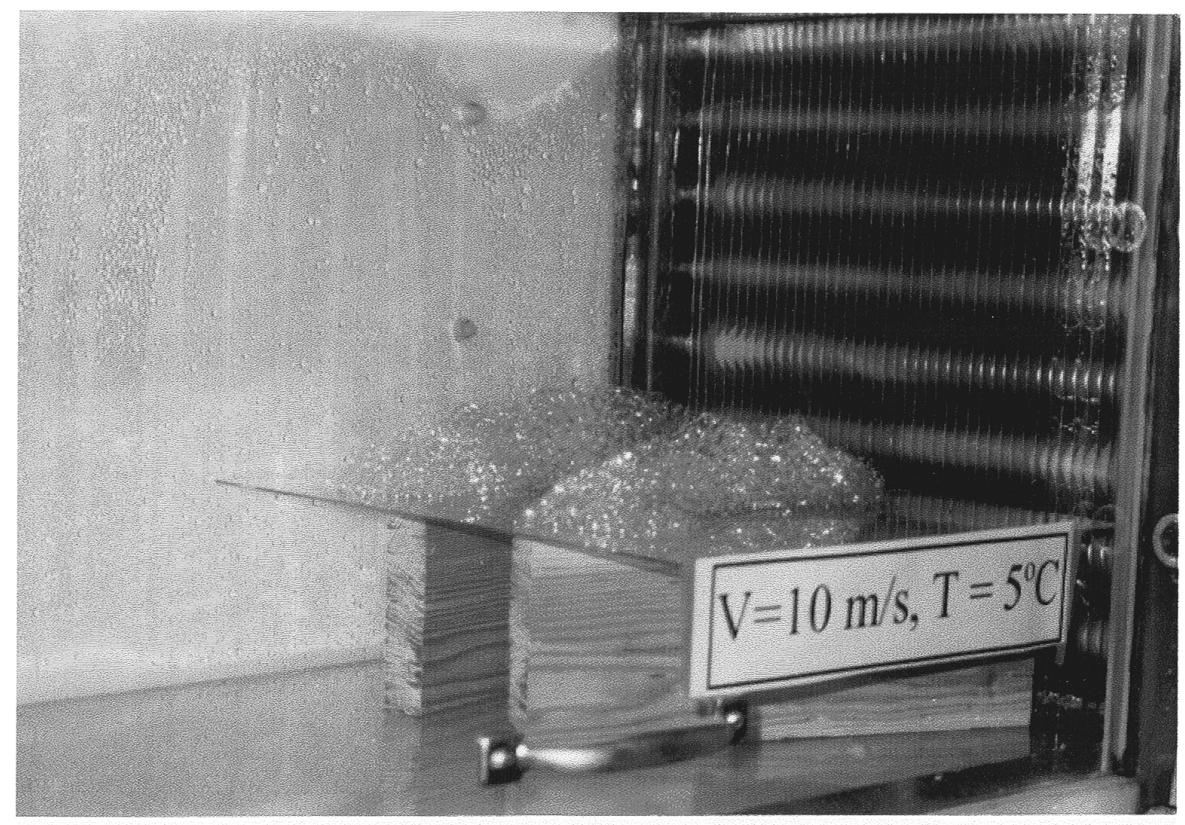




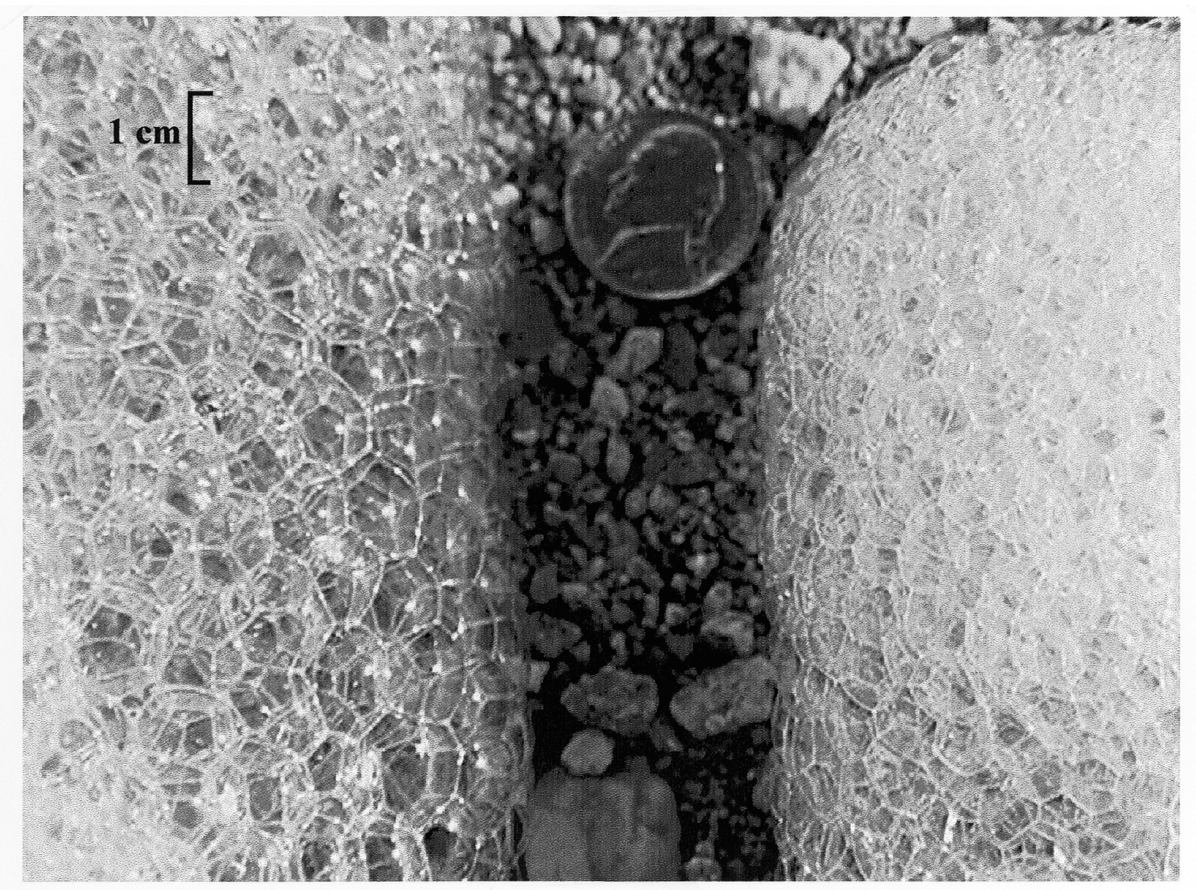

Fig. 4. Display of the typical bubble size of foam on the soil surface.

sion process took place after the first 5 h. The remaining water was important for frost protection, based on the experimental data discussed by Choi and
Giacomelli (1999).

A closed wind tunnel was used to test the foam stability under windy conditions at various temperatures. The wind tunnel provided a uniform temperature and $\mathrm{RH}$ airflow across the test section at air speeds varying from 0 to
$10 \mathrm{~m} \cdot \mathrm{s}^{-1}(32.8 \mathrm{ft} / \mathrm{s})$ and at air temperatures from $0{ }^{\circ} \mathrm{C}$ to $50{ }^{\circ} \mathrm{C}(32$ to 122 $\left.{ }^{\circ} \mathrm{F}\right)$. Details of the wind tunnel design and evaluation are described by Leon et al. (1998).

As shown in Fig. 3, foam 2 to 4 $\mathrm{cm}(0.8$ to 1.6 inch) thick on a horizontal Plexiglas plate maintained its structure under windy conditions, where the wind speed was set at $2,4,6$, 8 , and $10 \mathrm{~m} \cdot \mathrm{s}^{-1}(6.6,13.1,19.7,26.2$, and $32.8 \mathrm{ft} / \mathrm{s}$ ), respectively. The air temperature in the wind tunnel was maintained at a constant temperature for each run. Starting from room temperature $\left[\approx 21{ }^{\circ} \mathrm{C}\left(70{ }^{\circ} \mathrm{F}\right)\right]$, the air temperature was reduced to $0{ }^{\circ} \mathrm{C}(32$ $\left.{ }^{\circ} \mathrm{F}\right)$ using a heat exchanger and an isothermal bath. The relative humidity in the wind tunnel was within $50 \pm$ $10 \%$. In general, the results showed that the foam was stable at windy conditions. At 8 and $10 \mathrm{~m} \cdot \mathrm{s}^{-1}$, however, the upstream section of the fresh foam on the Plexiglas surface deformed

Fig. 5. The size of the row tunnel and the layout of the field experiment conducted in a single-layer polyethylene plastic film covered, wire hoopsupported, row tunnel.

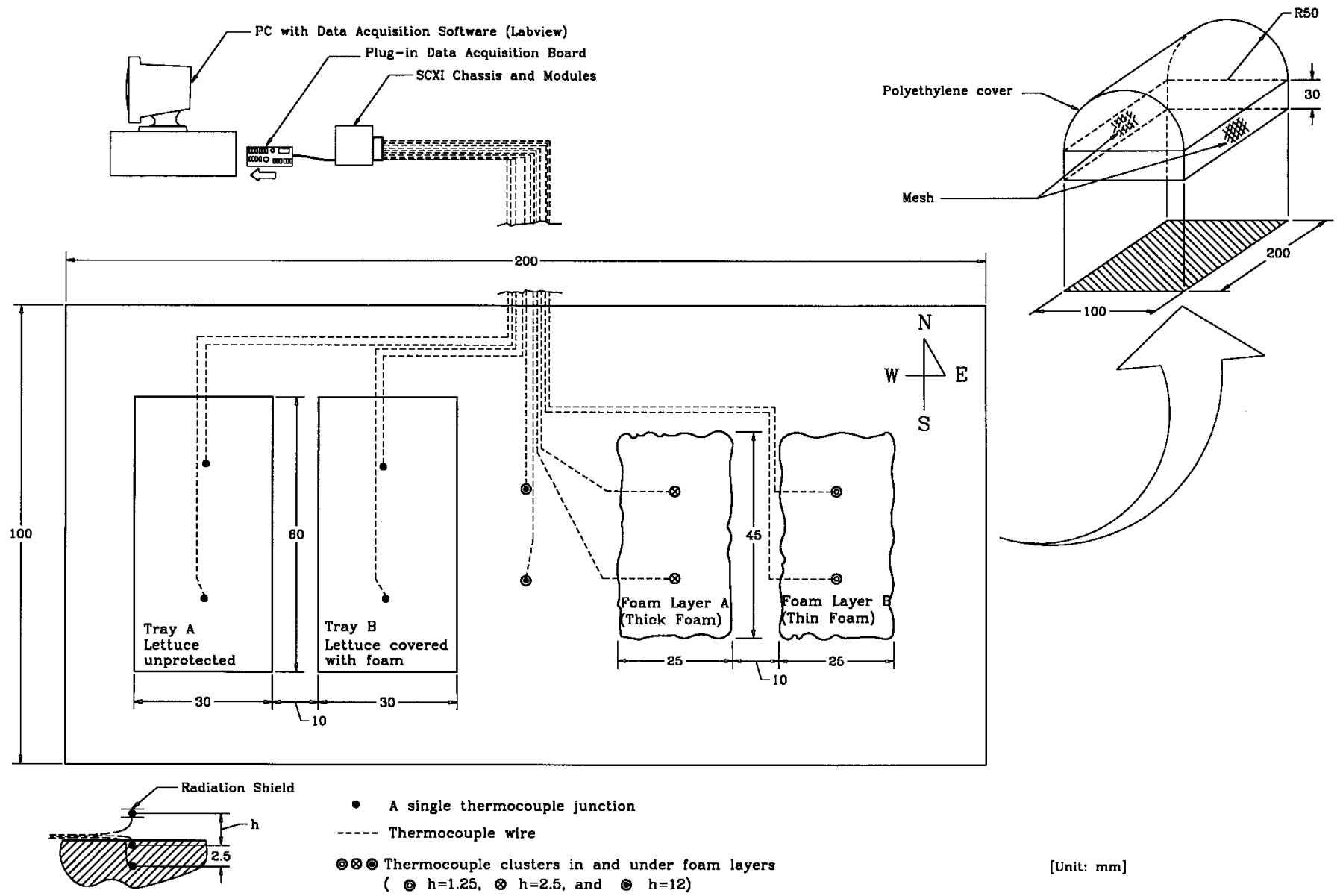




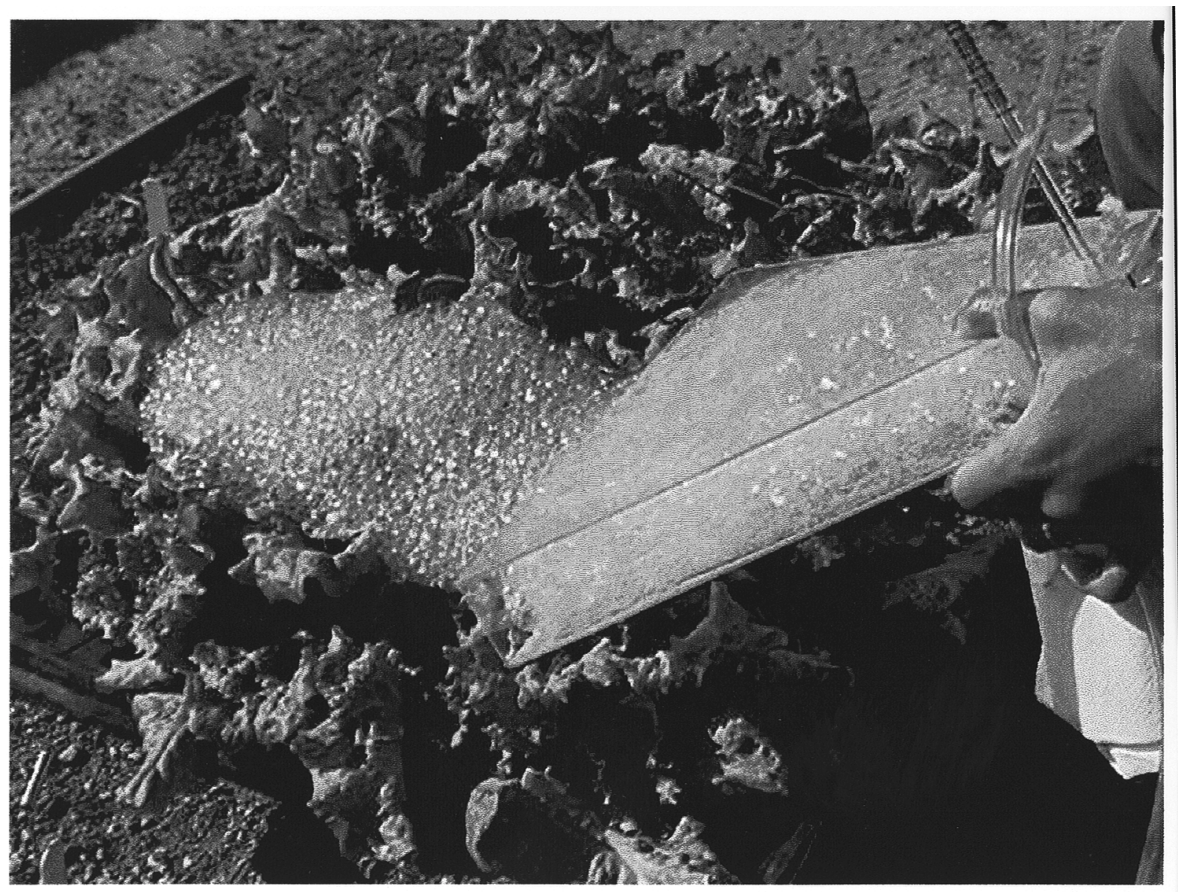

Fig. 6. Placement of $2 \mathrm{~cm}(0.8$ inch) foam over a tray $[30 \times 60 \mathrm{~cm}(11.8 \times$ 23.6 inch)] of lettuce (Lactuca sativa L. 'Black Seeded Simpson'), containing 15 plants.

noticeably toward the downstream. The gelatin in the foam had not gelled immediately after the foam generation. As the wind speed was reduced, the foam returned to its original shape. The foam became increasingly impervious to wind deformation as it gelled and solidified. Overall, the foam maintained its shape well at wind speeds up to $10 \mathrm{~m} \cdot \mathrm{s}^{-1}$.

Outdoor qualitative evaluation. Foam was first generated in two $1-\mathrm{L}$ (0.26-gal) beakers and placed outdoors under direct sunlight for a week in the early winter, where the highest daily temperature ranged from 15 to $20^{\circ} \mathrm{C}$ ( 59 to $68^{\circ} \mathrm{F}$ ). The foam survived with no sign of damage or degradation due to direct solar radiation or fluctuating air temperatures. A similar experiment was repeated with application directly on soil and on a metal screen [ mesh size: $1.25 \times 1.25 \mathrm{~cm}(0.5$ inch $)]$ without cover and left outdoors for several days. Figure 4 shows the typical bubble size of foam on the soil surface. Foam structure and shrinkage was observed for a few days. Foam remained on the ground and screen surface without noticeable volumetric changes. Although foam was directly exposed to the sun and wind, the level of foam shrinkage was about the same as in the laboratory.
Encouraged by the outcome of the preliminary tests, a field experiment was prepared at the University of Arizona Agricultural Research Center, Tucson. In the present paper, the experimental design and the qualitative evaluation of the foam properties will be described. The measurements and results of soil and plant temperature changes under the foam is discussed in the subsequent paper (Choi and Giacomelli, 1999).

The first field experiment was conducted in a protected environmental enclosure which included a singlelayer polyethylene plastic film covered, wire hoop-supported, row tunnel. The unheated tunnel was installed above a side-by-side test plot consisting of 1 ) foam applied to the ground as a soil mulch, and 2 ) foam applied to a tray of lettuce plants as a plant insulator. The primary purpose of the tunnel was to provide protection from rainfall. The size of the row tunnel and the layout of the experiment are shown in Fig. 5. In addition to the film, wire mesh was installed on both the north and south sides to allow for ventilation of fresh air when the plastic film was rolled up to a height of $30 \mathrm{~cm}$ ( $11.8 \mathrm{inch})$ from the ground on days of clear weather. The wire mesh was designed to protect the foam and lettuce from small animals. Before the installation of the tunnel and the foam, the soil was tilled and raked smooth.

Two trays $[30 \times 60 \mathrm{~cm}(11.8 \times$ 23.6 inch)] of lettuce (Lactuca sativa
L. 'Black Seeded Simpson'), containing 15 plants each, were placed sideby-side within the tunnel. A closed canopy of leaves existed within the tray. Foam was applied to cover one entire plant tray to a thickness of $\approx 2 \mathrm{~cm}$ (0.8 inch), using a nozzle as shown in Figs. 1 and 6. In a similar manner, foam was placed on the soil surface within the tunnel. The foam thickness for layers A and B (see Fig. 5 ) was $\approx 5$ and $2.5 \mathrm{~cm}$ ( 2 and 1 inch) respectively.

The experiment was continued for 2 weeks, and the structure and volume of each foam layer was continually monitored during the period. The daily temperature measured in the middle of the tunnel and at $12 \mathrm{~cm}(4.7$ inch) from the soil surface (see Fig. 5 ) ranged from $0{ }^{\circ} \mathrm{C}$ to $35^{\circ} \mathrm{C}$ (32 to 95 $\left.{ }^{\circ} \mathrm{F}\right)$. The nearby Arizona Meteorological Network weather station recorded the 2 -week $\min / \mathrm{max}$ ambient air temperatures as 0 and $25^{\circ} \mathrm{C}$ (32 and 77 $\left.{ }^{\circ} \mathrm{F}\right)$, respectively. The data collected at the AZMET station showed a total of $48.5 \mathrm{~mm}$ ( $1.9 \mathrm{inch}$ ) of rainfall, with 5 rainy days and a daily average relative humidity as high as $89 \%$.

The volume of the foam on lettuce was considerably reduced during this period, and only about a quarter of the original volume remained on the plant leaves at the end of the experiment. The main cause of the foam degradation appeared to be moisture trapped underneath from evapotranspiration. However, foam remained over $80 \%$ of the original coverage area; that is, the foam was substantially thinned due the moisture but with minimal lateral shrinkage. Thinning of the foam may reduce its insulating capability when used for freeze protection, but the $80 \%$ coverage with thin foam may still protect plants from frost damage. The foam coverage over dry soil remained nearly the same. The foam thickness shrank from $\approx 5$ to $4 \mathrm{~cm}$ (2.0 to 1.6 inch) for layer $\mathrm{A}$ and from 2.5 to $2.0 \mathrm{~cm}$ ( 1.0 to 1.8 inch) for layer B. The foam structure and longevity, therefore, were only slightly poorer than those produced under laboratory conditions. Thus the foam may be used as a ground cover for more than several weeks, if protected from rain.

Although the chemicals used for foam generation were known to be nonphytotoxic, the effect of the foam on the growth was carefully monitored nonetheless. The plants continued to grow well in the tunnel, whether 
or not covered with foam. There were no fungal or bacterial growth on the leaves or elsewhere.

The removal and ultimate fate of the foam was also considered. When the foam is applied to the trunks and canopies of trees, its removal may be a minor problem. However, the removal of the foam residue could be a major problem for crops such as strawberries (Fragaria Xananassa Duchesne) unless the foam residue self-disintegrated or was removed with water spray by harvest time. At the end experiment, it required a moderate water spray to wash the foam off the lettuce leaves. The foam would collapse immediately. However, a gel residue that remained on the leaves was not easily removed. On tree trunks or on the ground this is probably not a critical problem. The foam is biodegradable and various organisms will eventually remove it. However, if the foam is used to protect more delicate crops such as lettuce or strawberries, its removal may become a problem. Although the foam is nontoxic, it must be removed before the crops are sold. The gel residue dissolves in water, but only very slowly, unless the water is warm. The reduction of gelatin in the formulation may reduce this problem, although it may lead to a less durable foam. As mentioned earlier, a small amount of urea can reduce the gelation temperature of gelatin, and if the foam is used in cold weather it need not gel at 20 to $25^{\circ} \mathrm{C}$ ( 68 to $77^{\circ} \mathrm{F}$ ) as the current formula does. Reducing the gel temperature to 5 to $10^{\circ} \mathrm{C}\left(41-50{ }^{\circ} \mathrm{F}\right)$ may allow it to dissolve more quickly in tepid water. There is no overriding need to use a single formulation for all possible uses, and the composition could probably be adjusted for the end use.

\section{Conclusions and recommendations}

A foam formulation was developed by choosing sucrose as a bulking agent when gelatin is used as the polymeric material. The new foam was demonstrated to possess the physical properties necessary for practical use on field crops. The results demonstrate that the gelatin-based foam would become much more stable and can be formulated to last for several weeks by loading the aqueous solution with a bulking agent. The major properties of the newly developed foam include: long term stability, biode- gradability, adherence to plant canopy during application, and nontoxicity to plant or environment. Ability to serve as a conduction, convection and radiation barrier against freeze or frost protection is considered by Choi and Giacomelli (1999). A mechanism for large-scale field application of the developed foam has yet to be developed.

Possible agricultural applications of the long lasting foam are: 1) to protect young seedlings from freeze and frost after transplant, 2) to protect blossoms of fruiting trees from frost, 3 ) to prevent dormancy break of nursery crops from overheating within white overwintering structures, 4) to prevent the loss of trees such as citrus by protecting their trunks from freeze, and 5 ) to gain mulching benefits from direct applications over the soil. In addition, the long-lasting foam could contain pesticides, bioagents, carbon dioxide, or foliar fertilizer, thus providing other plant growth benefits.

\section{Literature cited}

Ashworth, E.N. 1992. Formation and spread of ice in plant tissues. Hort. Rev. 13:215-255.

Barfield, B.J. and J.F. Gerber. 1979. Modification of the aerial environment of plants. Amer. Soc. Agr. Eng. St. Joseph, Mich.

Bartholic, J.F. 1985. Thin layer foam for plant freeze protection. Proc. Fla. Hort. Soc. 85:299-302.

Braud, H.J. and J.L. Chesness. 1970. Physical properties of foam for protecting plants against cold weather. Trans. Amer. Soc. Agr. Eng. 13(1):1-5.

Braud, H.J., M. Esphahani, and J.L. Chesness. 1971. Generation of agricultural foam. Trans. Amer. Soc. Agr. Eng. 14(2):346-349.

Blackmon, W.J., M. Esphaphani, and H.J. Braud. 1972. Applying cotton herbicides in foam. La. Agr. 15(1):3.

Choi, C.Y., P.M. Waller, and T.M. Dennehy. 1997. Insect control with carbon dioxide foam. Trans. Amer. Soc. Agr. Eng. 40(5):1475-1480.

Choi, C.Y. and G.A. Giacomelli. 1999. Freeze and frost protection with aqueous foam - field experiments. HortTechnology 9(4):662-667.

Jensen, M.H. 1977. Energy alternatives and conservation for greenhouses. HortScience 12:14-24.

Leon, J.C., B. Babin, and C.Y. Choi. 1998. Design, construction, and development of a recirculating wind tunnel for agricultural experiments. Trans. Amer. Soc. Agr. Eng. 4l(1):213-218.

Krasovitski B., E. Kimmel, and I. Amir. 1995. A simulation of foam protection of plants against frost. J. Agr. Eng. Res. 61:155-163.

Krasovittski B., E. Kimmel, and I. Amir. 1996. Forecasting earth surface temperatures for optimal application of frost protection methods. J. Agr. Eng. Res. 63:93102.

Magnuson-Hawkins, S. and P. Gahlinger. 1996. Termites in paradise. Pest Control 64(2):72-73.

Polopolus, L.C. and D.L. Gunter. 1985. Natural disasters, competitive market forces, and the Florida orange juice industry. Citrus Ind. 77(9):46-50.

Rieger, M. Freeze protection for horticultural crops. 1989. Hort. Rev. 11:45-109.

Taylor, A.G., K.J. Kenny, E.P. Carney, and G.H. Gibbs. 1983. Development of a foam microenvironment for enhanced seedling establishment. HortScience 18(5):696697.

Ward, A.G. 1977. The science and technology of gelatin. Academic Press, London.

Whitney, R.W., L.O. Roth, J.A. Hair, and H.L. Gearhart. 1976. Pesticidal $\mathrm{CO}_{2}$ foam for tick control, Amer. Soc. Agr. Eng. Paper No. 76-2065. 